UCKER et al., v(10), no 10, p. 2102-2111, JAN-ABR, 2013.

Rev. Elet. em Gestão, Educação e Tecnologia Ambiental (e-ISSN: 2236-1170)

\title{
ELEMENTOS INTERFERENTES NA QUALIDADE DA ÁGUA PARA IRRIGAÇÃO
}

\author{
Fernando Ernesto Ucker ${ }^{1}$, Paula Barcelos Simões de Oliveira Lima², Mariel Fernanda Camargo ${ }^{3}$, \\ Diogo Silva Pena ${ }^{4}$, Claudio França Cardoso ${ }^{5}$, Adão Wagner Evangelista Pêgo ${ }^{6}$
}

\begin{abstract}
${ }^{1}$ Graduado em Engenharia Ambiental pelo Centro Universitário Franciscano. Mestre em Engenharia do Meio Ambiente ferucker@gmail.com

2 paulabsol.agro@gmail.com

3 marielcamargo@yahoo.com.br

${ }^{4}$ diogospena@hotmail.com

5 claudiofcardoso@yahoo.com.br

${ }^{6}$ Graduação em Engenharia Agrícola pela Universidade Federal de Lavras (1989), mestrado em Engenharia Agrícola (Irrigação e Drenagem) - Universidade Federal de Lavras (1999) e Doutorado em Engenharia Agrícola (Irrigação e Drenagem) pela Universidade Federal de Viçosa (2003). É Professor Adjunto e Sub-Coordenador do Programa de PósGraduação em Agronomia da Universidade Federal de Goiás (UFG). awpego@bol.com.br
\end{abstract}

http://dx.doi.org/10.5902/223611707540

\section{RESUMO}

Para o desenvolvimento da agricultura no mundo, a água é o recurso natural de maior relevância, uma vez que as novas tecnologias para aumento de produtividade das áreas agrícolas são dependentes da sua disponibilidade. Tal importância reflete-se nos altos índices de produtividade de áreas irrigadas, em que apenas $18 \%$ do total de áreas agrícolas correspondem a aproximadamente $40 \%$ da produção agrícola mundial. O objetivo deste trabalho foi, por meio de uma revisão bibliográfica, avaliar e discutir alguns dos principais tipos de água utilizados e atributos que podem interferir na qualidade da água destinada à irrigação. Concluiu-se que a utilização de águas de qualidade inferior, como residuárias ou a vinhaça, surge como alternativa para suprir a alta demanda hídrica em relação à baixa oferta. Porém, para isto, devem-se ter os conhecimentos dos principais atributos que posam interferir na qualidade da água destinada à irrigação, além do grau de perigo à saúde e ao meio ambiente.

Palavras-Chave: Agricultura, produtividade, água.

\section{ABSTRACT}

For the development of agriculture in the world, water is a natural resource of greater relevance, since new technologies to increase productivity of agricultural areas are dependent on their availability. This importance is reflected in the high productivity of irrigated areas, where only $18 \%$ of the total agricultural areas account for approximately $40 \%$ of global agricultural production. The objective of this study was, by means of a literature review, evaluate and discuss some of the main types of water used and attributes that can affect the quality of water for irrigation. It was concluded that the use of lower quality water, such as wastewater or stillage, is an alternative to meet the high demand for water in relation to low supply. But for this, one must have a knowledge of the main attributes that pose interfere with the quality of water for irrigation, and the degree of hazard to health and the environment.

Keywords: Agriculture, productivity, water. 
UCKER et al., v(10), no 10, p. 2102-2111, JAN-ABR, 2013.

Rev. Elet. em Gestão, Educação e Tecnologia Ambiental (e-ISSN: 2236-1170)

\section{INTRODUÇÃO}

A água é o bem mais precioso do planeta Terra, sendo o maior constituinte e o principal responsável pela vida, incluindo-se as plantas. Em função disso, segundo Postel et al. (1996), nesses últimos anos vem se tornando uma das maiores preocupações mundiais, levando-se a acreditar em uma iminente crise mundial de abastecimento.

As necessidades de água exigidas para atender ao crescimento populacional, ao desenvolvimento industrial e a expansão de áreas irrigadas têm aumentado substancialmente nas últimas décadas. No Brasil a demanda média de água para irrigação corresponde a $65 \%$ da demanda global, com variações nas diversas bacias hidrográficas (LIMA; FERREIRA; CHRISTOFIDIS, 1999).

Para o desenvolvimento da agricultura no mundo, a água é o recurso natural de maior relevância, uma vez que as novas tecnologias para aumento de produtividade das áreas agrícolas são dependentes da sua disponibilidade. Tal importância reflete-se nos altos índices de produtividade de áreas irrigadas, em que apenas $18 \%$ do total de áreas agrícolas correspondem a aproximadamente $40 \%$ da produção agrícola mundial (BROWN; RENNER; HALWEIL, 2000).

Uma das maneiras para o melhor aproveitamento das águas aptas para irrigação está em reduzir a quantidade aplicada em cada irrigação. Outra forma é usar a fração não consumida de água de irrigação já desviada, visto que ao nível de campo (Hill, 1994; Frederiksen, 1992), uma grande parte da água de irrigação aplicada (aproximadamente a metade), não é realmente consumida pelo cultivo e, portanto acaba como água de drenagem.

Segundo Almeida (2010), os principais parâmetros a serem avaliados na qualidade da água para irrigação contemplam os parâmetros físico-químicos e biológicos, que definem sua adequação ou não para o uso. Ainda segundo o autor, geralmente os principais atributos analisados são: $\mathrm{pH}$, condutividade elétrica, sólidos totais dissolvidos, e íons, como sódio, potássio, cálcio, magnésio, cloretos, sulfatos, carbonatos e bicarbonatos.

Com base no exposto acima, o objetivo deste trabalho é, por meio de uma revisão bibliográfica, avaliar e discutir alguns dos principais tipos de água utilizados e atributos que podem interferir na qualidade da água destinada à irrigação.

\section{Águas Residuárias}

Embora as fontes hídricas sejam abundantes, freqüentemente elas são mal distribuídas na superfície do planeta. Em alguns locais, a demanda é tão elevada em relação à oferta, que a disponibilidade de água superficial está sendo reduzida e os recursos subterrâneos estão sendo rapidamente esgotados (Setti et al., 2002). Para Trentin e Souza (2006), essa carência, no entanto, favorece a discussão sobre a necessidade urgente da utilização de águas de qualidade inferior, como as águas residuárias tratadas em um nível compatível com seu uso, em atividades menos exigentes em qualidade.

A disposição inadequada de águas residuárias é causa de grandes problemas ambientais, mesmo após esta ter passado por estações de tratamento de esgoto (ETE). As ETEs possuem, no geral, tratamento simplificado do esgoto gerado pela população ou pela indústria, e grande parte de contaminantes da água e do solo não são removidos, como nutrientes e coliformes. Se descartados em corpos d'água superficiais, as águas residuárias podem causar, por exemplo, o 
UCKER et al., v(10), no 10, p. 2102-2111, JAN-ABR, 2013.

Rev. Elet. em Gestão, Educação e Tecnologia Ambiental (e-ISSN: 2236-1170)

efeito chamado de eutrofização, conceituado por Mulqueen, Rodgers e Scally (2004) como sendo o crescimento excessivo de plantas aquáticas, a níveis que sejam considerados causadores de interferências aos usos desejáveis do corpo d'água.

Por isso, a disposição deste efluente no solo (reuso da água) vem ganhando espaço por apresentar, segundo Bastos e Mara (1992), ao menos três boas vantagens: o tratamento do efluente, o fornecimento de água e a disponibilidade de nutrientes para as culturas irrigadas. Ali (1987) e Hamoda e Al-Awabi (1996) afirmam ainda que estas águas podem ser utilizadas em regiões de pequena disponibilidade de água, como regiões semi-áridas, desde que se tenha o conhecimento específico do seu grau de perigo à saúde e ao meio ambiente.

As normas, os padrões e os códigos de prática de reuso agrícola no Brasil são realizados com base em diretrizes desenvolvidas por organismos internacionais. A Organização das Nações Unidas para Agricultura e Alimentação (FAO) estabeleceu diretrizes que são voltadas unicamente para os aspectos agrícolas e edafológicos em sistemas irrigados com efluentes. Segundo Trentin e Souza (2006), a Organização Mundial da Saúde publicou, em 1989, as "Diretrizes para o Uso de Esgotos em Agricultura e Aqüicultura", nas quais foram estabelecidos os critérios básicos para a proteção dos grupos de risco.

Autores como Braile e Cavalcanti (1979), Aguiar e Silva (1999), Mota (2000), Lucas Filho et al. (2001) e Trentin e Souza (2006), após obterem bons resultados no desenvolvimento de experimentos envolvendo o reuso da água, descreveram que esse recurso pode ser utilizado de forma planejada para produção de algumas culturas agrícolas. Aguiar e Silva (1999) afirmam ainda que o reuso intencional de despejos tratados não é uma prática nova, entretanto, ultimamente, tem havido interesse crescente em relação à necessidade de sua reutilização para inúmeras culturas.

Para Sousa et al. (2001), a adequação da água para irrigação ainda é muito subjetiva, no entanto deve-se sempre tentar identificar e avaliar alguns parâmetros que poderão produzir efeitos desagradáveis na relação água, planta e solo. Por exemplo, a água pode ser considerada adequada para certo tipo de solo ou cultura, mas inadequada para outros. Dessa forma, segundo Trentin e Souza (2006), sempre é importante analisar: as características físico-químicas, a qualidade sanitária da água, as características do solo, a tolerância das culturas a serem utilizadas, o clima local, o manejo da irrigação e a drenagem.

Hespanhol (2002) atribui números para alguns atributos da água residuária utilizada para fins agrícolas, como possuir um pH entre os limites 6,0 e 8,5 e valores da demanda bioquímica de oxigênio (DBO) de até $100 \mathrm{mg} / \mathrm{L}$. O autor recomenda, para melhor aceitação pelo usuário, que os valores de DBO devem ser de até $30 \mathrm{mg} / \mathrm{L}$ para irrigação de culturas consumidas cozidas e $10 \mathrm{mg} / \mathrm{L}$ para plantas consumidas cruas.

Blum (2003) acrescenta também que águas residuárias que possuem teores de sólidos em suspensão superiores a $30 \mathrm{mg} / \mathrm{L}$ podem causar entupimento em alguns sistemas de irrigação por aspersão, gotejamento e danos a sistemas de bombeamento. Segundo o mesmo autor, o recomendado é que os sólidos totais dissolvidos na água de irrigação para fins agrícolas não devem ultrapassar $500 \mathrm{mg} / \mathrm{L}$, mas podem chegar até $2.000 \mathrm{mg} / \mathrm{L}$ em condições especiais. Acima de $500 \mathrm{mg} / \mathrm{L}$, as irrigações devem ser realizadas com acompanhamento de práticas cuidadosas de manejo, pois podem afetar plantas mais sensíveis. 
UCKER et al., v(10), no 10, p. 2102-2111, JAN-ABR, 2013.

Rev. Elet. em Gestão, Educação e Tecnologia Ambiental (e-ISSN: 2236-1170)

\section{Salinidade}

A agricultura irrigada depende tanto da quantidade como da qualidade da água. A importância da qualidade da água só começou a ser reconhecida a partir do início deste século. A falta de atenção a este aspecto foi devido à disponibilidade de águas de boa qualidade e de fácil utilização, mas esta está mudando em vários lugares, em função do aumento de consumo por águas de qualidade, restando como alternativa o uso de águas de qualidade inferior (AYERS; WESTCOT, 1991). Dentre as características que determinam a qualidade da água para a irrigação, a concentração de sais solúveis ou salinidade é um fator limitante ao desenvolvimento de algumas culturas (BERNARDO, 1987).

Ferreira et al. (1998) estudaram o efeito da salinidade da água de irrigação e da lâmina de lixiviação na cultura da alface, verificando redução de $59 \%$ na produção máxima das plantas irrigadas com água a nível de $5,5 \mathrm{dS} \mathrm{m}^{-1}$ de salinidade. Blanco et al. (1999) observaram, em ambiente protegido, redução de $17,5 \%$ na produtividade da alface, para cada incremento unitário na condutividade elétrica do extrato saturado, e que a salinidade aumentou a porcentagem de matéria seca na planta e reduziu a sua altura.

Para Santana et al. (2007), o objetivo principal da irrigação é proporcionar às culturas, no momento oportuno, a quantidade de água necessária para seu ótimo crescimento, e assim evitar a diminuição dos rendimentos, provocada pela falta de água durante as etapas de desenvolvimento sensíveis à escassez.

Em áreas do Nordeste, onde a falta de água é uma realidade, é comum o uso de águas de cacimbas e de poços escavados no álveo dos rios, mediante irrigação por aspersão, molhando a folhagem. Essas águas nem sempre são adequadas para irrigação, contribuindo para o aparecimento de problemas de salinidade e, conseqüentemente, nutricionais, com prejuízos para os agricultores. A água de irrigação, mesmo de baixa salinidade, pode tornar-se um fator de salinização do solo, se não for manejada corretamente (AYERS; WESTCOT, 1991, LAZOF; BERNSTEIN, 1999).

De acordo com Santana et al. (2007), com as irrigações, os sais contidos na água acumulam-se na zona radicular, diminuindo a disponibilidade de água e acelerando sua escassez. A compreensão do processo de salinização permite encontrar formas de evitar seus efeitos e diminuir a probabilidade de redução de seus rendimentos (AYERS; WESTCOT, 1991).

Os principais problemas causados pela salinização do solo são a redução do potencial osmótico da solução do solo, diminuindo sua disponibilidade de água e acentuando a toxicidade de certos íons às plantas (BERNARDO, 1996). Os sais são transportados pelas águas de irrigação e depositados no solo, onde se acumulam à medida que a água se evapora ou é consumida pelas culturas. Estes sais do solo e da água reduzem a disponibilidade da água para as plantas, a tal ponto que afetam os rendimentos das culturas. Nem todas as culturas respondem igualmente à salinidade, algumas produzem rendimentos aceitáveis a níveis altos de salinidade e outras são sensíveis a níveis relativamente baixos. Esta diferença deve-se à melhor capacidade de adaptação osmótica que algumas culturas tem, o que permite absorver, mesmos em condições de salinidade, maior quantidade de água (AYERS; WESTCOT, 1991).

Segundo Souza (1995), solos normais podem se tornar improdutivos se receberam sais solúveis em excesso devido a irrigações mal conduzidas com águas salinas. Mesmo com um bom controle da qualidade da água de irrigação (o que raramente é feito na prática) há um contínuo resíduo de sais no solo. 
UCKER et al., v(10), no 10, p. 2102-2111, JAN-ABR, 2013.

Rev. Elet. em Gestão, Educação e Tecnologia Ambiental (e-ISSN: 2236-1170)

A qualidade da água para irrigação é avaliada não apenas pelo seu conteúdo total de sais, mas, também, pela composição individual dos íons presentes. Alguns cátions e ânions, quando em excesso, podem trazer prejuízos ao solo (pelo efeito direto na sodificação) e às plantas cultivadas, dependendo do grau de tolerância destas aos sais (AYERS; WESTCOT, 1991, RICHARDS, 1995, ZONN, 1986). Burt ET al. (1995) atentam para outros aspectos importantes na avaliação da qualidade da água para a irrigação, como a possibilidade de precipitação de resíduos, principalmente quando a irrigação é praticada em condutos pressurizados e há interação da água com produtos fertilizantes (misturas), aplicados via fertirrigação. Para os autores, a aplicação de sais (fertilizantes minerais) e defensivos (herbicidas, fungicidas, acaricidas, nematicidas, etc.) via água de irrigação, pode apresentar problemas de precipitação ou volatilização, dependendo da qualidade da água a ser usada. A eficiência da adubação pode ser diminuída quando cuidados especiais não são tomados para melhorar as condições de equilíbrio químico nas águas em um programa de fertirrigação de uma cultura.

Segundo Gervásio (2000), a produção comercial da alface americana é prejudicada pelo aumento na salinidade da água de irrigação e do extrato saturado, e caracterizada pela formação de cabeças pequenas e pouco compactas.

Santana et al (2007), afirma que o aumento unitário da salinidade acima de $0,2 \mathrm{dS} \mathrm{m}^{-1} \mathrm{da}$ condutividade elétrica do extrato de saturação do solo, proporciona redução de $17 \%$ na produção comercial da alface.

Conclui-se do exposto que, para um monitoramento do nível de salinidade, dos riscos de precipitação de resíduos nas tubulações e da elevação do problema da sodicidade do solo há necessidade do conhecimento prévio da qualidade da água utilizada.

As análises de rotina efetuadas em laboratórios de água, determinações de $\mathrm{pH}$ e condutividade elétrica (CE), fornecem subsídios para se avaliar a possibilidade de precipitação de sais e a indução da salinidade em função da prática da irrigação (GERVÁSIO, 2000).

O cálculo da razão de adsorção de sódio (RAS) assume papel preponderante, posto que a combinação CE e RAS serve para avaliar os perigos que a água oferece, respectivamente, em termos de indução de salinidade e aumento nos teores de sódio na solução do solo. O uso da RAS, como proposto originalmente pelo Laboratório de Salinidade do Solo dos Estados Unidos (RICHARDS, 1954) tem sido, no entanto, freqüentemente criticado por subestimar o risco de sodicidade e por não levar em consideração outros íons (ânions como $\mathrm{HCO}_{3}{ }^{-}$e $\mathrm{CO}_{3}{ }^{2-}$ ) sugerindo-se métodos de cálculos alternativos, como os da RAS ajustada (RAS aj) e da RAS corrigida (RAS cor). Cada modalidade de cálculo tem como objetivo avaliar melhor o provável efeito do sódio existente na água em relação ao solo em que a mesma vai ser utilizada na irrigação (WILCOX; DURUM, 1967, RHOADES; LOVEDAY, 1990; HOLANDA; AMORIM, 1997); por outro lado, os cálculos de valores de "ajuste" ou "correção" da RAS, posteriormente sugeridos, envolvem ábacos por vezes complexos a nível de trabalho de rotina em um laboratório; daí a necessidade de se obter formas mais simplificadas de estimativas a partir de análises de rotina em um laboratório de análises de água para fins de irrigação.

Empregando-se métodos computacionais, esta tarefa pode ser obtida avaliando-se uma grande massa de dados analíticos em laboratórios de análises de rotina para as regiões em que os mesmos prestam tais serviços. 
UCKER et al., v(10), no 10, p. 2102-2111, JAN-ABR, 2013.

Rev. Elet. em Gestão, Educação e Tecnologia Ambiental (e-ISSN: 2236-1170)

Ferro

A qualidade da água para irrigação é avaliada pela concentração de sais e pela composição individual dos íons, e alguns em excesso podem trazer prejuízo ao solo e às plantas (AYRES; WESTCOT, 1991; RICHARDS, 1995; ZONN, 1986). Para irrigação com condutos pressurizados, e ainda, com intenção de fertirrigação, é importante avaliar a água para a possibilidade de precipitação de resíduos (BURT et al., 1995). Dentre os possíveis componentes da água para irrigação o ferro em alta concentração pode acarretar tanto em toxicidade para as plantas, quanto entupimento dos emissores e tubulações.

Nos estados de Goiás, Minas Gerais e São Paulo existem fontes de água naturalmente ricas em ferro (ALVES, 2008). Nakayama e Bucks (1986) estabeleceram limites para o risco de obstruções dos emissores, sendo que para o elemento ferro concentrações acima de 1,5 ppm é considerado alto. Para Hernandez e Petinari (1998) teores de ferro acima de 0,5 $\mathrm{mg} \mathrm{L}^{-1}$ já podem obstruir tubulações. Segundo Bar (1995) qualquer água que contenha ferro na concentração maior que $0,5 \mathrm{mg} \mathrm{L}^{-1}$ não pode ser utilizada nos sistemas por gotejamento, a não ser que receba tratamento químico.

O ferro é um nutriente essencial às plantas, mas pode causar toxidez quando a disponibilidade na solução do solo for muito alta. A toxidez por ferro é uma das limitações, por exemplo, ao rendimento do arroz irrigado por alagamento tanto por efeito direto do ferro no interior da planta como pelo efeito indireto sobre a absorção de outros nutrientes essenciais. $O$ ferro é tóxico para os vegetais nas concentrações acima de $5 \mathrm{mgL}^{-1}$, quando indisponibiliza fósforo e molibidênio acarretando em deficiência nutricional (ALMEIDA, 2010).

O ferro é encontrado principalmente nas águas subterrâneas e apresenta-se nas formas de bicarbonato ferroso $\left(\mathrm{FeHCO}_{3}\right)$, sulfato ferroso $\left(\mathrm{FeSO}_{4}\right)$ ou complexado na forma de matéria orgânica. Em contato com o ar oxida formando hidróxido férrico $\mathrm{Fe}(\mathrm{OH})_{3}$. E nesta forma causa o entupimento dos sistemas de irrigação e ainda, a formação de mucilagem devido a presença de ferrobactérias (ALVES, 2008).

Para a remoção do ferro na água a ser utilizada para irrigação, Azevedo Neto (1991) resalta a importância de se conhecer a forma como o elemento se apresenta na água, para então escolher o processo de eliminação. Estando o ferro dissolvido (não ligado à matéria orgânica) basta a simples aeração da água. Mas estando o ferro ligado à matéria orgânica além da aeração é necessário o contato com produtos adsorventes (ADAD, 1971).

Para irrigação a aeração seguida de sedimentação é o método mais seguro para remover o ferro da água (ALVES, 2008). O método permite a incorporação de grande quantidade de oxigênio que transforma o óxido ferroso em óxido de ferro e assim, precipitado. Quando esta metodologia não é suficiente, há o emprego de oxidantes químicos, sendo, normalmente utilizado o hipoclorito de sódio. 
UCKER et al., v(10), no 10, p. 2102-2111, JAN-ABR, 2013.

Rev. Elet. em Gestão, Educação e Tecnologia Ambiental (e-ISSN: 2236-1170)

Vinhaça

Apesar de se tratar de um caso de água residuária, a vinhaça pode ser detalhada em um capítulo a parte, visto seu alto poder de contaminação no ambiente. Há cerca de 30 anos em alta atividade no país, a cana-de-açúcar avançou muito além do papel tradicional da agricultura como fonte alimentícia, entrando no universo da agroenergia. Porém, no processo de fabricação do álcool é gerado um novo subproduto, a vinhaça.

De acordo com Freire e Cortez (2000), a vinhaça é caracterizada como um efluente de destilarias com alto valor fertilizante em solos, porém com alto poder poluente quando descartada em corpos d'água. Sua força poluente pode chegar a cerca de cem vezes a do esgoto doméstico, decorrente da sua riqueza em matéria orgânica, baixo $\mathrm{pH}$, alta demanda biológica de oxigênio (DBO), além da corrosividade e altas temperaturas.

A criação do Programa Nacional do Álcool (Proálcool) em 1975, recebeu investimentos significativos somente na década de 80 após o segundo choque econômico do petróleo em 1979, ampliando as áreas de produção de cana-de-açúcar (Saccharum sp.) em novas fronteiras, especialmente no Centro-Oeste do Brasil. Em contrapartida, aumentou a produção de vinhaça, na proporção de dez a dezoito litros de vinhaça por litro de álcool, representando um imenso potencial de poluição do meio ambiente (SILVA, 2007).

Segundo Rosseto (1987), em tempos passados, a vinhaça era lançada nos rios, causando danos ambientais. A matéria orgânica lançada num curso de água representa alimento para a fauna aquática, mas somente até o ponto em que o consumo de oxigênio dissolvido na água não seja limitante para a sobrevivência, ocasionando morte por asfixia. Do mesmo modo, quantidades elevadas de resíduos nas águas alteram o pH do meio (normalmente próximo da neutralidade), também ocasionando a morte da fauna.

Por isso, a utilização da vinhaça como input de nutrientes no solo tornou-se uma alternativa viável e de grandes estudos. O uso da vinhaça, como fonte de nutrientes, matéria orgânica e água, foi uma das grandes revoluções no manejo da cultura. Segundo Resende et al. (2002), atualmente, toda a vinhaça produzida é reutilizada na adubação dos canaviais.

A adição da vinhaça ao solo corresponde, em primeira instância, a uma adubação orgânica (ROSSETTO, 1987). Glória e Orlando Filho (1983) enumeraram os seguintes efeitos da vinhaça no solo: a) elevação do $\mathrm{pH}$; b) aumento da disponibilidade de alguns íons; c) aumento da capacidade de troca catiônica; d) aumento da capacidade de retenção de água; e e) melhoria da estrutura física do solo. Silva (2007) acrescenta ainda que a vinhaça deve ser vista como agente de aumento da população e atividade microbiana no solo.

Estudando a utilização de vinhaça como fertilizante e condicionador de solos, Cunha et al. (1981) observaram que a acumulação de potássio no perfil não foi significativa, ficando retido na camada de 0,50 m de profundidade. Canellas et al. (2003), trabalhando em Cambissolo, não verificaram aumentos de $\mathrm{K}^{+}$e $\mathrm{Ca}^{2+}$, da CTC e do nitrogênio, mas observaram aumento nos teores de cobre e ferro na camada de 0,20-0,40 m de profundidade. Constataram, ainda, aumento na fração de ácidos fúlvicos de até $13 \%$ na camada de $0,40 \mathrm{~m}$, o que poderia indicar tanto a evolução química dos compostos orgânicos como o transporte desta fração para camadas mais profundas de solo. 
UCKER et al., v(10), no 10, p. 2102-2111, JAN-ABR, 2013.

Rev. Elet. em Gestão, Educação e Tecnologia Ambiental (e-ISSN: 2236-1170)

\section{Conclusões}

Com base no exposto acima, conclui-se que a utilização de águas de qualidade inferior surja como alternativa para suprir a alta demanda hídrica em relação a baixa oferta, desde que se tenham os conhecimentos dos principais atributos que posam interferir na qualidade da água destinada à irrigação, além do grau de perigo à saúde e ao meio ambiente.

\section{Referências}

ADAD, J. M. T. Qualidade da água: aspectos físicos, físico-químicos e químicos. Belo Horizonte: UFMG, 1971.135 p.

AGUIAR, E. M.; SILVA, D. A. Aspectos produtivos e morfológicos do capim elefante (Pennisetum purpureum, Schum.) Cv. roxo de botucatu submetidos a esgoto sanitário semi-tratados. In: ENCONTRO DAS ÁGUAS, 2., 1999, Montevidéu. Anais... Montevidéu: Instituto Interamericano de Cooperación para la Agricultura, Uruguay, 1999.

ALI, B. I. Irrigation in arid regions. Journal of Irrigation and Drainage Engeneering of ASCE, NewYork, v.113, n.2, p.173183, 1987.

ALMEIDA, O. A. de. Qualidade da água de irrigação. Cruz das Almas: Embrapa Mandioca e Fruticultura, 2010.

ALVES, D. N. B. Remoção de ferro em água de irrigação através de filtragem em areia e zeólita. 2008. Tese (Doutorado em Engenharia de Água e Solo) - Engenharia Agrícola, Universidade Federal de Lavras, Lavras, 2008.

AYERS, R. S.; WESTCOT, D. W. A qualidade da água na agricultura. Campina Grande: UFPB, 1991. 218 p.

AZEVEDO NETO, J. M. Tratamento de águas de abastecimento. São Paulo: Universidade de São Paulo, 1991.

BAR, I. Iron control system for drip irrigation microirrigation for a change world: Conserving resources/Preserving the environment. In: INTERNACIONAL MICROIRRIGATION CONGRESS, 15., 1995, Orlando Proceedings... 1995, p. $239-243$.

BASTOS, R. K. X.; MARA, D.D. Irrigacion de hortalizas com águas residuales: Aspectossanitários. In: CONGRESO INTERAMERICANO DE INGENIERIA SANITARIA YAMBIENTAL, 23., 1992, La Habana. Anais... La Habana: Association Interamericano delngenieriaSanitaria y Ambiental, 1992. p.22-8.

BERNARDO, S. Manual de irrigação. 6. ed. Viçosa: UFV, 1996. 596 p.

BLUM, J. R. C. Critérios e padrões de qualidade da água. In: MANCUSO, P.C.S.; SANTOS, H.F. dos. (Ed.). Reúso de água. Barueri: Manole, 2003. p. 125-174.

BRAILE, P. M.; CAVALCANTI, J.E.W.A. Manual de tratamento de águas residuárias industriais. São Paulo, 1979.

BROWN, L.R.; RENNER, M.; HALWEIL, B. Sinais vitais 2000: as tendências ambientais que determinarão nosso futuro. Salvador: UMA, 2000. 196 p.

FREDERIKSEN, H. D. Drought planning and water efficiency implication in water resources management. Washington: The Word Bank, 1992. p. 25-33 (Word Bank Technical Paper, 185).

BURT, C.; O'CONNOR, K.; RUEHR. Fertigation. San Luis Obispo: California Polytechnic State University, 1995. 296p.

CANEllaS, L. P.; Velloso, A. C. X.; MARCIANO, C. R.; RAMALHO, J. F. G. P.; ROUMJANEK, V. M.; REZENDE, C. E.; SANTOS, G. A. Propriedades químicas de um Cambissolo cultivado com cana-de-açúcar, com preservação de palhiço e adição de vinhaça por longo tempo. Revista Brasileira de Ciência do Solo, Viçosa, v. 27, n. 5, p. 935-944, 2003. 
UCKER et al., v(10), no 10, p. 2102-2111, JAN-ABR, 2013.

Rev. Elet. em Gestão, Educação e Tecnologia Ambiental (e-ISSN: 2236-1170)

CUNHA, R. C. A.; COSTA, A. C. S.; MASET FILHO, B.; CASARINI, D. C. P. Effects

of irrigation with vinasse and dynamics of its constituents in the soil: I - physical and chemical aspects. Water Science Technology, London, v. 19, n. 8, p. 155-165, 1981.

FREIRE, W. J.; CORTEZ, L. A. B. Vinhaça de cana-de-açúcar. Guaíba: Agropecuária, 2000. 203 p.

GLÓRIA, N. A.; ORLANDO FILHO, J. Aplicação de vinhaça como fertilizante. São

Paulo: Coopersucar, 1983. $38 \mathrm{p}$.

HAMODA, M. F.; AL-AWADI, S. M. Improvement of effluent quality for reuse in a dairy farm. Water Science and Technology, Londres, v. 33, n. 10, p. 79-85, 1996.

HERNANDEZ, F. B. T.; PETINARI, R. A. Qualidade de água para irrigação localizada. In: CONGRESSO BRASILEIRO DE ENGENHARIA AGRÍCOLA, 27., 1998, Poços de Caldas. Anais... Lavras: UFLA/SBEA, 1998. B2, p. 58 - 60

HESPANHOL, I. Potencial de Reúso de Água no Brasil: Agricultura, Indústria, Municípios, Recarga de Aqüíferos. Rev. Bras. Rec. Hid., Porto Alegre, v. 7, n. 4, p. 75-95, 2002.

HILL, R. W. Consumptive use of irrigated crop in Utah. Research Report. Logan: Agricultural Experimental Station, 1994. p. 121-126. (Research Report, 145).

LAZOF, D. B.; BERNSTEIN, N. Effects of salinization on nutrient transport to lettuce leaves: consideration of leaf developmental stage. The New Phytologist, Cambridge, Inglaterra, v. 144, n. 1, p. 85-94, 1999.

LIMA, J. E. F. W.; FERREIRA, R. S. A.; CHRISTOFIDIS, D. O uso da irrigação no Brasil. In: FREITAS, M. A. V. (org). O Estado das águas no Brasil: perspectivas de gestão e informação de recursos hídricos. Brasília: ANEEL, MME, MMA/SRH, OMM, PNUD, 1999. p. 73-82.

LUCAS FILHO, M. et al. Disposição de esgoto tratado através do escoamento subsuperficial em solo preparado com cobertura vegetal. In: ENCUENTRO DE LAS AGUAS, 3., 2001, Santiago. Anais... Santiago, Chile, 2001.

NAKAYAMA, F.S.; BUCKS, D.A. Trickle irrigation for crop production. St. Joseph: ASAE, 1986. 383p.

MOTA, S. Aplicação de esgoto doméstico em irrigação. In: REÚSO DE ÁGUAS: A EXPERIÊNCIA DA UNIVERSIDADE FEDERAL DO CEARÁ. 2000, Fortaleza. Anais... Fortaleza: UFC, 2000.

MULQUEEN, J.; RODGERS, M.; SCALLY, P. Phosphorus transfer from soil to surface waters.Agricultural Water Management, v. 66, n. 1, p. 107-122, 2004.

POSTEL, S. L.; DAILY, G. C.; EHRLICH, P. R. Human appropriation of renewable fresh water. Science, v. 271, p. 785-788, 1996.

RESENDE, M.; CURI, N.; REZENDE, S. B.; CORRÊA, G. F. Pedologia: base para distinção de ambientes. 4. ed. Viçosa: NEPUT, 2002. 338 p.

RICHARDS, R. A. Improving crop production on salt affected soils: by breeding or management? Expl. Agric. v. 31, p. $395-408.1995$

ROSSETTO, A. J. Utilização agronômica dos subprodutos e resíduos da indústria açucareira e alcooleira. In: PARANHOS, S. B. (Ed.). Cana-de-açúcar: cultivo e utilização. Campinas: Fundação Cargill, 1987. v. 2, p. 435-504.

SANTANA, M. J.; CARVALHO, J. A.; SOUZA, K. J.; SOUSA, A. M. G.; VASCONCELOS, C. L.; ANDRADE, L. A. B. Efeitos da salinidade da água de irrigação na brotação e desenvolvimento inicial da cana-de-açúcar (saccharum spp) e em solos com diferentes níveis texturais. Ciênc. Agrotec, Lavras, v. 31, n. 5, p. 1470-1476, 2007. 


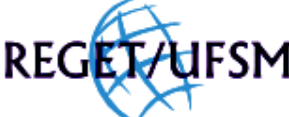

UCKER et al., v(10), no 10, p. 2102-2111, JAN-ABR, 2013.

Rev. Elet. em Gestão, Educação e Tecnologia Ambiental (e-ISSN: 2236-1170)

SETTI, A. A. et al. Introdução ao Gerenciamento de Recursos Hídricos. 3. ed. Brasília: ANEEL/ANA, 2002.

SILVA, M. A. S. da. Impactos da aplicação de vinhaça sobre as propriedades químicas do solo e de seu efluente. 2007. 92 f. Tese (Doutorado em Agronomia: Solo e Água) Escola de Agronomia e Engenharia de Alimentos, Universidade Federal de Goiás, Goiânia, 2007.

SOUSA, J. T. et al. Desempenho da cultura do arroz irrigado com esgotos sanitários previamente tratados. Rev.Bras. Eng. Amb., Campina Grande, v. 5, n. 1, p. 107-110, 2001.

SOUZA, M. R. de. Comportamento do feijoeiro (Phaseolus vulgaris L. CV Eriparza) submetido a diferentes níveis de salinidade da água de irrigação. 1995. 94 f. Dissertação (Mestrado em EngenhariaAgrícola) Universidade Federal de Lavras, Lavras, 1995.

TRENTIN, C. V.; SOUZA, J. L. M. Possibilidade de utilização da irrigação com água residuária em torno das principais estações de tratamento de efluentes da Região Metropolitana de Curitiba, Estado do Paraná, Brasil. Acta Sci. Agron, Maringá, v. 28, n. 2, p. 291-298, 2006.

ZONN, S. V. Saline (haloomorphic) soils. In: ZONN, S. V. Tropical and subtropical soil science. Moscow: Mir Publishers, 1986. p. $365-379$. 